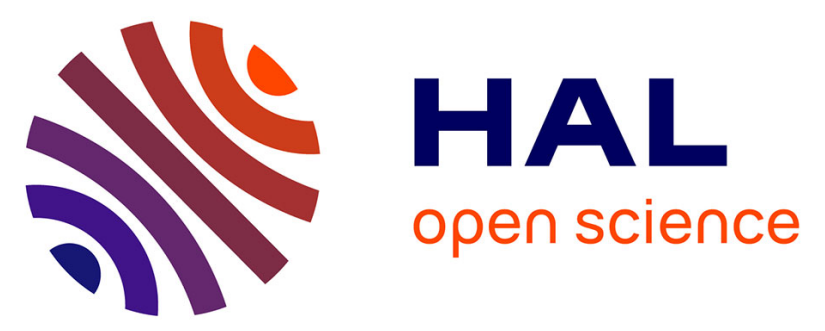

\title{
Detection and characterization of biogenic selenium nanoparticles in selenium-rich yeast by single particle ICPMS
}

Javier Jiménez-Lamana, I. Abad-Álvaro, Katarzyna Bierla, F. Laborda, J. Szpunar, Ryszard Lobinski

\section{To cite this version:}

Javier Jiménez-Lamana, I. Abad-Álvaro, Katarzyna Bierla, F. Laborda, J. Szpunar, et al.. Detection and characterization of biogenic selenium nanoparticles in selenium-rich yeast by single particle ICPMS. Journal of Analytical Atomic Spectrometry, 2018, 33 (3), pp.452-460. 10.1039/c7ja00378a . hal-01736851

\section{HAL Id: hal-01736851 \\ https://hal.science/hal-01736851}

Submitted on 8 Feb 2021

HAL is a multi-disciplinary open access archive for the deposit and dissemination of scientific research documents, whether they are published or not. The documents may come from teaching and research institutions in France or abroad, or from public or private research centers.
L'archive ouverte pluridisciplinaire $\mathbf{H A L}$, est destinée au dépôt et à la diffusion de documents scientifiques de niveau recherche, publiés ou non, émanant des établissements d'enseignement et de recherche français ou étrangers, des laboratoires publics ou privés. 

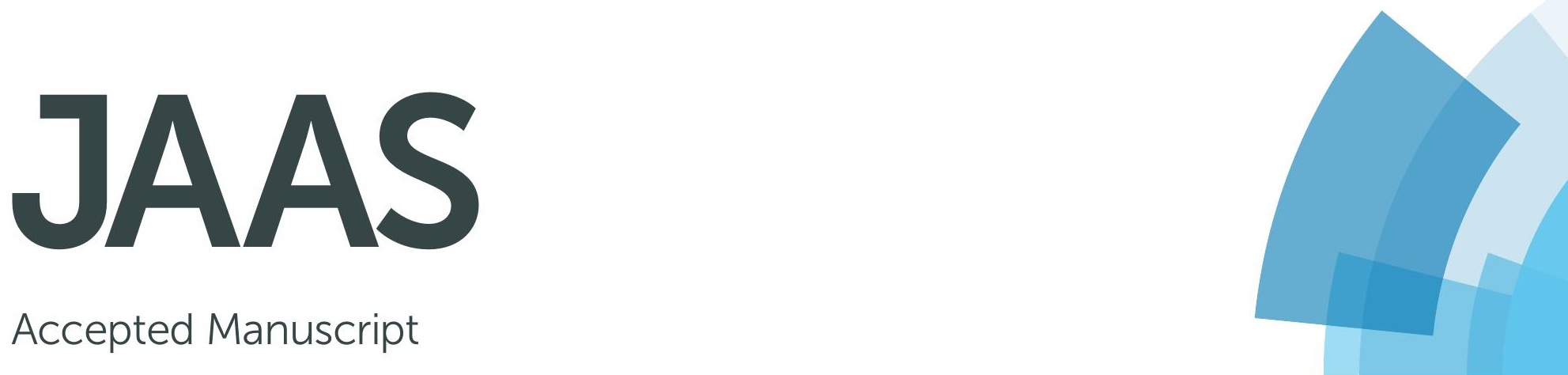

\section{Accepted Manuscript}

This article can be cited before page numbers have been issued, to do this please use: J. JiménezLamana, I. Abad-Álvaro, B. Katarzyna, F. Laborda, J. Szpunar and R. Lobinski, J. Anal. At. Spectrom., 2018, DOI: 10.1039/C7JA00378A.

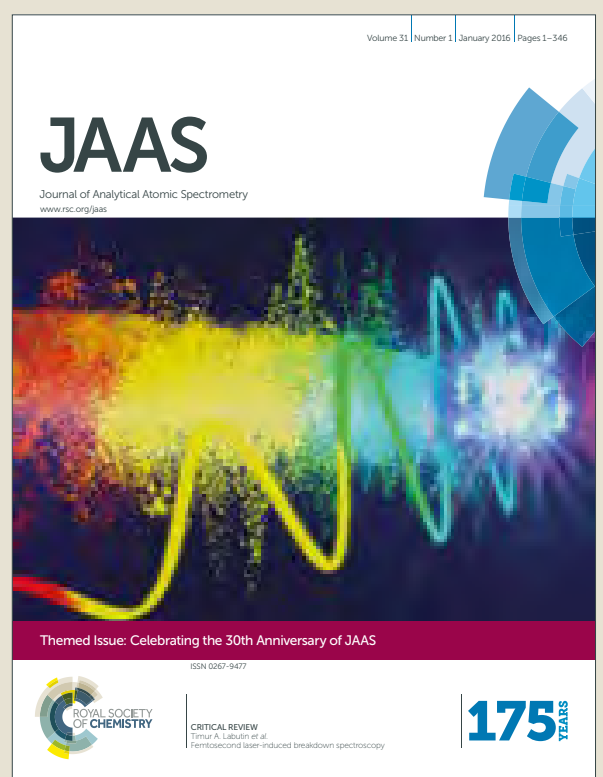

This is an Accepted Manuscript, which has been through the Royal Society of Chemistry peer review process and has been accepted for publication.

Accepted Manuscripts are published online shortly after acceptance, before technical editing, formatting and proof reading. Using this free service, authors can make their results available to the community, in citable form, before we publish the edited article. We will replace this Accepted Manuscript with the edited and formatted Advance Article as soon as it is available.

You can find more information about Accepted Manuscripts in the author guidelines.

Please note that technical editing may introduce minor changes to the text and/or graphics, which may alter content. The journal's standard Terms \& Conditions and the ethical guidelines, outlined in our author and reviewer resource centre, still apply. In no event shall the Royal Society of Chemistry be held responsible for any errors or omissions in this Accepted Manuscript or any consequences arising from the use of any information it contains. 


\section{Detection and characterization of biogenic selenium}

\section{2 nanoparticles in selenium-rich yeast by single particle ICPMS}

3

4 Javier Jiménez-Lamana ${ }^{a,{ }^{*}}$, Isabel Abad-Álvaro ${ }^{b}$, Katarzyna Bierla ${ }^{a}$, Francisco Laborda ${ }^{b}$, 5 Joanna Szpunar ${ }^{\text {a }}$, Ryszard Lobinski ${ }^{\text {a }}$

6

7 aaboratoire de Chimie Analytique Bio-inorganique et Environnement (LCABIE), UMR 5254-

8 IPREM, CNRS-UPPA, Hélioparc, Pau, France

9 broup of Analytical Spectroscopy and Sensors (GEAS), Institute of Environmental Sciences, (IUCA) University of Zaragoza, Zaragoza, Spain

11

12 Corresponding author

*Telephone: +33540175037. E-mail: j.jimenez-lamana@univ-pau.fr

ABSTRACT

16 A method based on single particle inductively coupled plasma mass spectrometry (SP-ICPMS) was

17 developed for the analysis of commercial Se-rich yeasts, to confirm the occurrence of selenium nanoparticles in these food supplements. A considerable reduction of the background levels was achieved by combining data acquisition at microsecond dwell times and the use of $\mathrm{H}_{2}$ reaction cell, improving by a factor of 10 the current state-of-the-art methodology, and bringing size detection 
21 limits down to $18 \mathrm{~nm}$ for selenium nanoparticles. The presence of nanoparticulate selenium was

22 unveiled by size-exclusion chromatography ICPMS, detecting a selenium peak at the exclusion

23 volume of the column showing absorption at the wavelength corresponding to selenium

24 nanoparticles. SP-ICPMS allowed to confirm the presence of Se-nanoparticles, as well as to

25 calculate the nanoparticle size distribution, owing to the information about the shape and elemental

26 composition of the nanoparticles obtained by transmission electron microscopy (TEM) and energy

27 dispersive X-ray spectroscopy (EDS), respectively. These results reveal the significance of 28 nanoparticles in the speciation of metals and metalloids in biological samples and the capability of 29 SP-ICPMS in combination with TEM-EDS to carry out these analyses.

30

\section{1. Introduction}

32 Tailored metal/metalloid biogenic nanoparticles with specific physiochemical properties have been 33 shown to be highly toxic to several pathogenic bacteria and may offer an attractive alternative for 34 therapy of infections by antibiotic resistant bacteria. ${ }^{1,2}$ In particular, selenium nanoparticles (SeNPs) 35 synthesized by microorganisms, such as bacteria, fungi or yeast were demonstrated to possess 36 antibacterial, antiviral and antioxidant properties. ${ }^{1,2}$ The process of the $\mathrm{Se}^{\circ}$ nanoparticle formation is 37 based on the reduction of a toxic selenite $\left(\mathrm{SeO}_{3}{ }^{2-}\right)$ or selenate $\left(\mathrm{SeO}_{4}{ }^{2-}\right)$ to the less toxic (for the host 38 organism) elemental selenium through the intra- or extracellular formation of SeNPs with a typical 39 spherical shape and a diameter of 50-400 nm.,4

40 Yeast is not only recognised as a model system to study selenite or selenate metabolic 41 detoxification pathways, ${ }^{5}$ but it has also been the basis of an important biotechnological process of 42 their conversion to selenoamino acids, in particular to selenomethionine. ${ }^{6}$ Indeed, yeast 
43 (Saccharomyces cerevisiae) grown on selenite or selenate media, accumulates up to $3000 \mu \mathrm{g} \mathrm{g}^{-1}$ of

44 selenium, and has been used as a food and feed supplement, ${ }^{6}$ and at high doses ( $>200 \mu \mathrm{g}$ Se/day) in

45 prostate and colon cancer prevention treatments. ${ }^{7}$ The subsequent authorizations obtained by several

46 companies for the commercialization of Se-rich yeast were preceded by the development of

47 analytical methods for the specific identification and quantification of the different chemical forms

48 of selenium present (speciation) of which the state-of-the art was reviewed. ${ }^{8}$

49 The currently available analytical methods allow the determination of selenomethionine

50 [with a relatively high confidence owing to the availability of a certified reference material (SELM-

51 1)], ${ }^{9}$ selenocysteine and a water soluble metabolome fraction. ${ }^{8}$ They also allow the determination of

52 the residual (non-reacted) selenite or selenate, referred to as "inorganic selenium" of which the

53 presence below $2 \%$ is considered by the legislators as a proof of an "organic" character of Se-rich

54 yeast. ${ }^{10}$ Our experience over the past decade, through the analysis of several hundred samples from

55 about 20 different suppliers, indicates that the selenium mass balance for the identified species

56

57

58

59

60

61

62

63 rarely exceeds $90 \%$ which would suggest the presence of unaccounted forms of selenium.

To our best knowledge, $\mathrm{Se}^{\circ}$ has never been quantified in yeast, although there were some attempts to its quantification in garlic ${ }^{11}$ and in Thunbergia alata ${ }^{12}$ using operationally defined or chemical conversion methods. Nanometer-sized deposits were reported in yeast cells grown in the presence of selenium by using X-ray radiation fluorescence spectroscopy ${ }^{13}$ without being characterized more deeply or quantified. We are putting forward here a hypothesis that a certain amount of selenium may be present in Se-rich yeast supplements as SeNPs and are proposing the development of an analytical method for its verification. 
To date SeNPs produced by microorganisms have been characterized by transmission

65 electron microscopy (TEM), ${ }^{3,4,14-19}$ X-Ray diffraction (XRD) ${ }^{20}$ and atomic force microscopy

66 (AFM). ${ }^{19,20}$ For instance, TEM analyses provided evidence of the formation of electron-dense

67 granules in Se-treated microorganisms which were absent in the control ones. ${ }^{3,4}$ The presence of

68 selenium in these granules could be confirmed by energy dispersive X-ray spectroscopy (EDS)

69 while the absence of peaks from other elements indicated the presence of Se in the elemental state

70 rather than as a selenide. ${ }^{3,4}$ TEM was also applied for the characterization of SeNPs produced by

71 Bacillus cereus, ${ }^{14}$ the soil bacterium Pseudomonas putida KT2440, ${ }^{15}$ the filamentous bacterium

72 Streptomyces sp. ES2-5, ${ }^{16}$ the rhizobacterium Azospirillum brasilense, ${ }^{17,18}$ and a genetically

73 modified Pichia pastoris strain. ${ }^{19}$ In the latter case, results were confirmed by AFM. On the other

74 hand, SeNPs of an average size of $21 \mathrm{~nm}$ produced by bacterial isolate Pseudomonas aeruginosa

75 strain JS-11 were characterized by XRD. ${ }^{20}$ The morphology and size of the nanoparticles were

76 further validated by AFM. Recently, an alternative to TEM measurements was proposed by using

77 the capabilities of asymmetrical flow field-flow fractionation (AF4) coupled on- and off-line with

78 different detectors, such as diode array (DAD), dynamic light scattering (DLS) or inductively

79 coupled plasma mass spectrometry (ICP-MS) ${ }^{21,22}$. For example, biogenic SeNPs synthesized by

80 lactic acid bacteria (LAB) were characterized by AF4 coupled on-line with DLS and results in good

81 agreement with those obtained by TEM and nanoparticle tracking analysis (NTA) were obtained ${ }^{22}$.

82 A major drawback of these methods is their difficulty to detect, characterize and quantify SeNPs at

83 low concentrations $\left(\mu \mathrm{g} \mathrm{kg}^{-1}\right)$.

84 This limitation can be overcome by single particle inductively coupled plasma mass 85 spectrometry (SP-ICPMS), which is one of the emerging techniques for the detection, 
86 characterization and quantification of nanoparticles. ${ }^{23}$ The theoretical basis of SP-ICPMS was

87 outlined by Degueldre et al. ${ }^{24}$ and further developed by Laborda et al. ${ }^{25}$ SP-ICPMS is able to

88 discriminate (detect and quantify) dissolved versus particulate forms of the element in a sample, and

89 to provide information about the element mass content per particle. Moreover, if additional

90 information about their composition, shape and density is available, the size of the particles can be

91 obtained, as well as their number and mass concentration. ${ }^{26}$

92 The feasibility of SP-ICPMS is compromised by the achievable size detection limits. For 93 elemental selenium nanoparticles, a detection limit of $200 \mathrm{~nm}$ was estimated theoretically. ${ }^{27}$ This is 94 by far too high for the microorganisms related applications, although this size detection limit was 95 calculated by using the low abundant $(9.36 \%){ }^{76}$ Se isotope, due to inherent problems for selenium 96 determination by ICPMS because of spectral interferences. This problem can usually be overcome 97 by using mathematical correction equations ${ }^{28}$ or reaction/collision cells ${ }^{29}$.

The objective of this work is the development of a method for the detection and size characterization of selenium nanoparticles by single particle ICPMS with the aim to reduce 100 considerably the size-detection limits predicted up to now. ${ }^{27}$ The method is going to be used to verify the occurrence of inorganic nanoparticulate selenium in Se-rich yeasts, confirming the hypothesis that this species must be included in the speciation schemes of this element in Se-rich 103 yeasts.

\section{Experimental}

106

\subsection{Standards, samples and reagents}


107 Diluted suspensions of gold and selenium nanoparticles were prepared from commercially available

108 materials. A reference gold nanoparticle suspension RM 8013 of 60 -nm nominal diameter was 109 obtained from NIST (NIST, Gaithersburg, MD). Suspensions of selenium nanoparticles of nominal 110 diameters of 50 and $100 \mathrm{~nm}$ were purchased from Nanocs (Nanocs, New York, NY). Dilutions were 111 prepared in ultrapure water by accurately weighing $( \pm 0.1 \mathrm{mg})$ aliquots of the stock suspensions 112 after 1 min sonication (Branson 2510, Bransonic, Danbury, CT; nominal power and frequency: 100 $113 \mathrm{~W}, 42 \mathrm{kHz}+/-6 \%$ ). After dilution and before each analysis, the suspensions were bath sonicated for $1141 \mathrm{~min}$ (same power and frequency). Longer sonication times were not used to avoid excessive 115 heating of the suspensions. Aqueous selenium solutions were prepared from a standard stock 116 solution of $10000 \mathrm{mg} \mathrm{L}^{-1}$ (Sigma-Aldrich, St. Louis, MO) by dilution in ultrapure water. Ultrapure 117 water (18.2 $\mathrm{M} \Omega \mathrm{cm})$ was obtained from a Milli-Q system (Millipore, Guyancourt, France). 118 Selenium-rich Brewer's yeast samples (obtained from a commercial provider), corresponding to a 119 yeast strain Saccharomyces cerevisiae, grown in different concentrations of selenium were used.

\subsection{SP-ICPMS analysis and data processing}

122 An Agilent 7900 Inductively Coupled Plasma Mass Spectrometer (ICPMS) (Agilent, Tokyo, Japan) 123 was used throughout. The sample introduction system consisted of a concentric nebulizer and a 124 quartz cyclonic spray chamber. Default instrumental and data acquisition parameters are listed in 125 Table 1. Settling time during data acquisition was eliminated and the total acquisition time was $60 \mathrm{~s}$ 126 in all experiments.

Nebulization efficiency was calculated according to the particle frequency method 128 developed by Pace et al. $^{30}$ The sample flow rate was calculated daily by measuring the mass of 
water taken up by the peristaltic pump for two minutes. This operation was repeated three times and

130 the average value used for calculations. Under the experimental conditions used along this work, the 131 nebulization efficiency at a sample flow rate of $0.35 \mathrm{~mL} \mathrm{~min}^{-1}$ was $3.5 \%$.

Dwell times of $5 \mathrm{~ms}$ and $100 \mu$ s were studied and isotopes ${ }^{80} \mathrm{Se}$ and ${ }^{78} \mathrm{Se}$ monitored. Single

133 Nanoparticle Application Module for ICPMS MassHunter software (Agilent), as well as in-house

134 developed programs based on MatLab (MathWorks, Natick, MA) and Excel (Microsoft, Redmond, 135 OR) spreadsheets were used for data processing. OriginPro 8 data analysis software (OriginLab 136 Corporation, Northampton, MA) was also used.

Table 1 Default instrumental and data acquisition parameters for single particle ICPMS

\begin{tabular}{ll}
\hline Instrumental parameters & \\
\hline RF Power & $1550 \mathrm{~W}$ \\
Argon gas flow rate & $15 \mathrm{~L} \mathrm{~min}^{-1}$ \\
Plasma & $0.9 \mathrm{~L} \mathrm{~min}^{-1}$ \\
Auxiliary & $1.10 \mathrm{~L} \mathrm{~min}^{-1}$ \\
Nebulizer & $5.0 \mathrm{~mL} \mathrm{~min}{ }^{-1}$ \\
Reaction cell flow rate $\left(\mathbf{H}_{2}\right)$ & $0.35 \mathrm{~mL} \mathrm{~min}^{-1}$ \\
Sample uptake rate & \\
\hline Data acquisition parameters & $5 \mathrm{~ms}, 100 \mu \mathrm{s}$ \\
\hline Dwell time & 12000,600000 \\
Readings per replicate & - \\
Settling time & $60 \mathrm{~s}$ \\
Total acquisition time & ${ }^{78} \mathrm{Se},{ }^{80} \mathrm{Se},{ }^{197} \mathrm{Au}$ \\
\hline
\end{tabular}


140

141

142

143

144

145

146

147

148

149

150

151

152

153

154

155

156

157

158

159

160

\subsection{Size Exclusion chromatography - ICPMS}

A Superdex Peptide 10/300 GL column (GE Healthcare, Pittsburgh, PA) was coupled to an Agilent 7700x ICPMS (Agilent) instrument. Chromatographic separations were performed by using a model 1200 series HPLC pump (Agilent) as a delivery system. The exit of the column was connected in series to an UV-visible detector (Agilent) and the ICPMS instrument.

\subsection{Transmission electron microscopy}

Samples were prepared on holey carbon films on mesh copper grids. A few microliters of each sample were dropped on the grid and left to dry completely. Images were obtained using a FEI TECNAI 12 (FEI, Hillsboro, OR) and recorded using an ORIUS SC1000 11MPx (GATAN, Pleasanton, CA) CCD camera. The microscope is equipped with an energy-dispersive X-ray analysis system for elemental analysis.

\subsection{Procedures}

2.5.1. Acid digestion. The content of total selenium in selenium nanoparticle suspensions and Se-rich yeast samples was determined by ICPMS following acid digestion in a DigiPREP digestion system (SCP Science, Quebec, Canada). $250 \mu \mathrm{L}$ of $\mathrm{H}_{2} \mathrm{O}_{2}$ (VWR International, Fontenaysous-Bois, France) and $1 \mathrm{~mL}$ of conc. $\mathrm{HNO}_{3}$ (Baker, Deventer, Netherlands) were added to $250 \mu \mathrm{L}$ of sample. The digestion was performed at $65^{\circ} \mathrm{C}$ for $4 \mathrm{~h}$. After digestion the volume was made up to $50 \mathrm{~mL}$ so that the final $\mathrm{HNO}_{3}$ concentration was $2 \%(\mathrm{v} / \mathrm{v})$. Digestions were made in duplicate. Blanks were run in parallel with the samples, as well as Certified Reference Material SELM-1 
161 (National Research Council of Canada) was analysed in order to validate the total selenium 162 determination after acid digestion.

2.5.2. Enzymatic digestion. The digestion/extraction procedure included four steps: (1) 200 $\mathrm{mg}$ of a Se-rich yeast sample were suspended in $5 \mathrm{~mL}$ of water, bath sonicated for $1 \mathrm{~h}$ and centrifuged at $4500 \times \mathrm{g}$ for $10 \mathrm{~min}$; (2) the pellet was resuspended with a solution of $5 \mathrm{~mL}$ of $\mathrm{mM}$ at $\mathrm{pH} 7.5$, incubated at $25^{\circ} \mathrm{C}$ for $17 \mathrm{~h}$ and centrifuged at $4500 \mathrm{x}$ g for $10 \mathrm{~min}$; (3) the pellet was resuspended with a solution of $5 \mathrm{~mL}$ of protease (Sigma Aldrich) of $4 \mathrm{mg} \mathrm{L}^{-1}$ in Tris $30 \mathrm{mM}$ at $\mathrm{pH}$ 7.5 , incubated at $37^{\circ} \mathrm{C}$ for $17 \mathrm{~h}$ and centrifuged at $4500 \mathrm{x}$ g for $10 \mathrm{~min}$; (4) finally, the pellet was resuspended with a solution of $5 \mathrm{~mL}$ of sodium dodecyl sulphate (SDS, Sigma Aldrich) of 4\% $(\mathrm{m} / \mathrm{v})$, bath sonicated for $1 \mathrm{~h}$ and centrifuged at $4500 \mathrm{xg}$ for $10 \mathrm{~min}$. The supernatant was recovered and kept at $4{ }^{\circ} \mathrm{C}$ until analysis. One of the samples was subjected to an extra step: $1 \mathrm{~mL}$ of the SDS

173 extract was digested with a $1 \mathrm{~mL}$ protease solution of $4 \mathrm{mg} \mathrm{L}^{-1}$ in Tris $30 \mathrm{mM}$ at $\mathrm{pH} 7.5$, incubated 174 at $37^{\circ} \mathrm{C}$ for $17 \mathrm{~h}$ and centrifuged at $4500 \mathrm{x}$ g for $10 \mathrm{~min}$.

\section{Results and discussion}

\section{3.1. Selection of instrumental parameters for the improvement of size detection limits}

178 In SP-ICPMS, the size detection limit is critically dependent on the detection efficiency (ions 179 arriving to the detector with respect to the atoms in the plasma) and the background signal. Isobaric 180 and matrix/plasma polyatomic interferences, as well as dissolved species of the element measured 181 contribute to the continuous baseline in the time scans recorded in single particle mode. The most 
182

183

184

185

186

187

188

189

190

191

192

193

194

195

196

197

198

199

200

201

202

203 significant effect of a high baseline level is the loss of capability to identify particles with smaller amounts of the element measured, and hence the increase in the size detection limits. ${ }^{31}$

Selenium has 6 naturally occurring stable isotopes with abundances from 0.9 to $49.6 \%$ which are severely interfered mostly by Ar containing ions (Table S1). This problem has been overcome in quadrupole ICPMS by selecting less-interfered isotopes (e.g., ${ }^{82} \mathrm{Se}$ ) or by using mathematical correction equations. ${ }^{28}$ However, the use of reaction/collision cells ${ }^{29}$ should allow the use of the most abundant isotopes ${ }^{80} \mathrm{Se}$ and ${ }^{78} \mathrm{Se},{ }^{32,33}$ which are otherwise severely interfered by Ar dimers. The fact that the size detection limit value of $200 \mathrm{~nm}$ was estimated by Lee et al. ${ }^{27}$ using relatively-low abundant ${ }^{76} \mathrm{Se}(9.36 \%)$ suggests a large margin for improvement of the size detection limit of SeNPs if a high abundance isotope is selected and the polyatomic interferences removed. Finally, a decrease of dwell times from milliseconds to microseconds would result in a proportional reduction of the absolute baseline level ${ }^{34}$ and hence of the related noise. The above considerations were the basis of the method optimization strategy.

3.1.1. Choice of the isotope: effect of the collision cell. Our goal was to use one of the two most abundant selenium isotopes, ${ }^{78} \mathrm{Se}$ and ${ }^{80} \mathrm{Se}$, by reducing or eliminating the background interferences. Apart from the contribution of residual $\mathrm{Kr}$ in the Ar gas supply, the main plasma background contributions at masses 78 and 80 arise from Ar dimers. Indeed, the direct measurement at $\mathrm{m} / \mathrm{z} 80$ is not possible, as the background exceeds $6.4 \times 10^{7} \mathrm{cps}$ (time scans are shown in Fig. S1); a considerable background $\left(4.1 \times 10^{4} \mathrm{cps}\right)$ is also observed for ${ }^{78} \mathrm{Se}$. The use of collision/reaction cells to reduce argon-based polyatomic interferences has been previously reported in literature (but never for selenium in the single-particle mode), with the use of different gases such as methane $\mathrm{e}^{35-37}$ or a $\mathrm{He}-\mathrm{H}_{2}$ mixture. ${ }^{32}$ For instance, the potentially interfering argon dimers at the selenium masses 
$20474,76,78$ and 80 were reduced by approximately five orders of magnitude by using methane as 205 reactive cell gas. ${ }^{35}$ In our case, the pressurization of the collision cell with $\mathrm{H}_{2}\left(5.00 \mathrm{~mL} \mathrm{~min}^{-1}\right)$ led to 206 a $5 \times 10^{3}$-fold decrease in the background for ${ }^{78} \mathrm{Se}$ (down to $8 \mathrm{cps}$ ) and $7 \times 10^{5}$-fold for ${ }^{80} \mathrm{Se}$ (down 207 to $90 \mathrm{cps})$. Therefore, the use of the reaction cell leads to an important decrease of background 208 signals in both cases, being more pronounced at mass 80 . If sensitivities at mass 78 with and 209 without reaction cell are compared, an improvement of more than twice is observed using $\mathrm{H}_{2}$, which 210 is explained through the isotopic abundance of the isotopes. Table 2 summarizes the background 211 signals, the standard deviation of the associated noise, the signal-to-noise ratio and the sensitivity 212 (slope of the calibration curve for selenium water solution) which allowed the calculation of the 213 attainable concentration detection limits for the different selenium isotopes in the standard and 214 collision/reaction cell modes.

216 Table 2 Background signals, associated noise (expressed as standard deviation of background), 217 signal-to-noise ratio, sensitivity and attainable concentration detection limits for the different 218 selenium isotopes when measured with and without collision/reaction cell. Dwell time: $100 \mu \mathrm{s}$

\begin{tabular}{|c|c|c|c|c|c|c|}
\hline Se & $\mathrm{H}_{2}$ cell & $\begin{array}{l}\text { Background } \\
\text { (cps) }\end{array}$ & $\begin{array}{l}\text { Noise } \\
\text { (cps) }\end{array}$ & $\begin{array}{l}\text { Sensitivity } \\
\left(\text { cps L } \mu g^{-1} \text { ) }\right.\end{array}$ & $\mathbf{S} / \mathbf{N}$ & $\begin{array}{l}\mathbf{L D} \\
\left(\mu \mathrm{g} \mathrm{L^{-1 }}\right)\end{array}$ \\
\hline 80 & No & 63700000 & 2160000 & $\mathrm{O} / \mathrm{R}$ & $\overline{---}$ & $\overline{---}$ \\
\hline 78 & No & 41300 & 18800 & 7700 & 0.04 & 7.33 \\
\hline 80 & Yes & 90 & 995 & 40600 & 40.8 & 0.074 \\
\hline 78 & Yes & 8 & 300 & 17800 & 59.33 & 0.051 \\
\hline
\end{tabular}

219

220 3.1.2. Dwell time. When a sufficiently diluted suspension of nanoparticles is introduced 221 into the plasma, each particle produces an individual pack of ions which is detected as such. By 
222 using dwell times in the millisecond range (3-10 ms), events corresponding to the detection of 223 single particles are detected as single pulses, whereas they are detected as transient signals when 224 microsecond dwell times $(<100-200 \mu \mathrm{s})$ are selected. On the other hand, the dissolved species 225 present together with the residual plasma background, produce a constant signal in the detector. The 226 intensity of this signal, expressed in counts, decreases proportionally if dwell times are shortened ${ }^{32}$ 227 whereas the corresponding noise diminishes according to the square root of the background (for 228 signals below ca. 1000 counts, shot noise being the main contribution to the noise). ${ }^{26}$

Fig. 1 compares the time scans at dwell times of $5 \mathrm{~ms}$ and $100 \mu \mathrm{s}$ with reaction cell 230 recorded for water and for a 50-nm selenium nanoparticle suspension with a nanoparticle number 231 concentration of $\sim 1.85 \times 10^{8} \mathrm{~L}^{-1}$. When working in the milliseconds regime (Figs. 1a, c), an 232 averaged baseline signal of 3.4 counts was measured. However, when the dwell time was shortened 233 to $100 \mu \mathrm{s}$ (Figs. 1b, d) the intensity of the baseline was close to zero. Therefore, working in the 234 microsecond range instead of the millisecond range, makes it possible to reduce the contribution of 235 the background and thus to improve the size detection limits. 

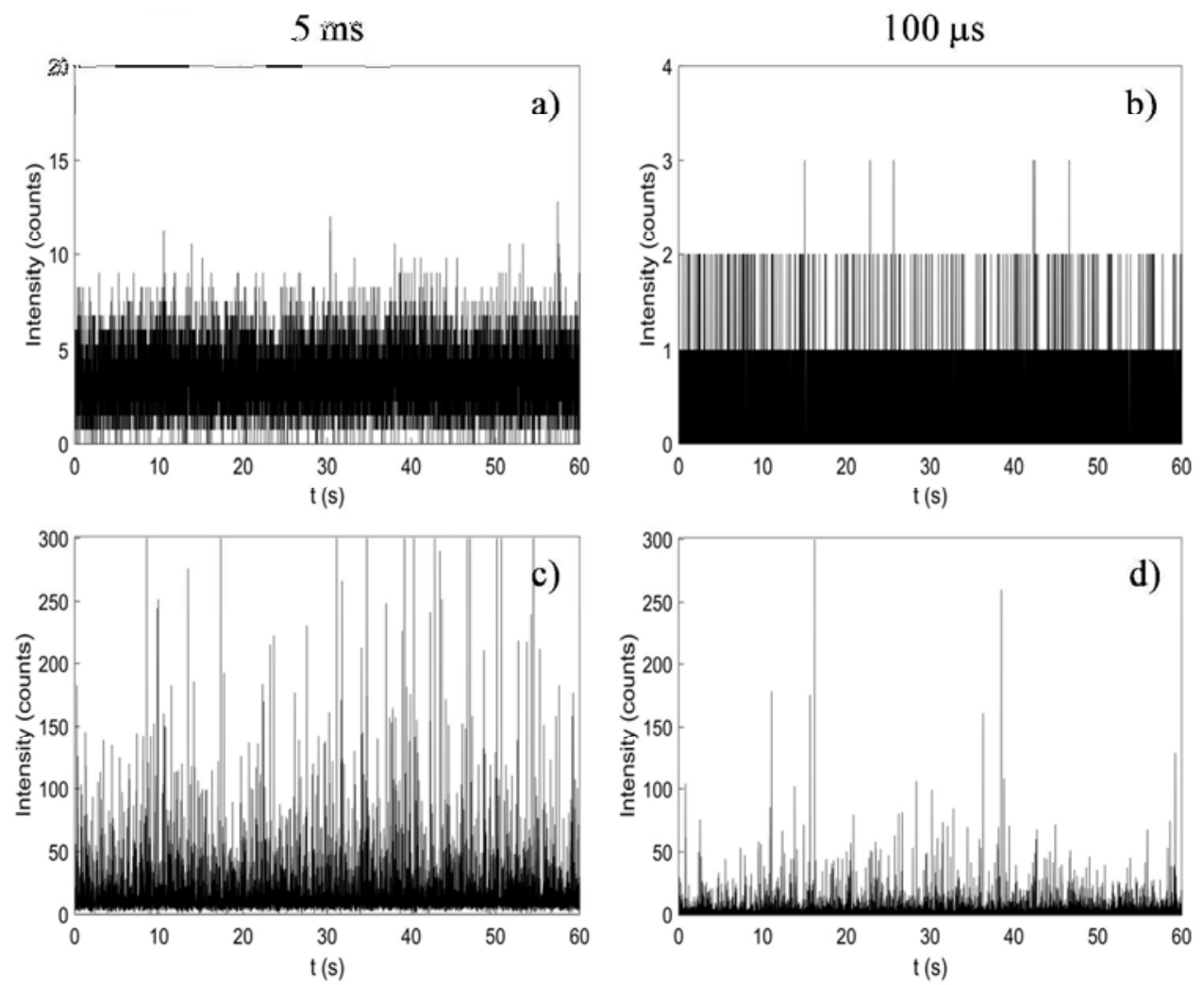

238 Fig. $1{ }^{80}$ Se time scans of (a-b) ultrapure water, (c-d) 50 -nm nanoparticle suspension of $1.85 \times 10^{8} \mathrm{~L}^{-}$

239 . Dwell times: $5 \mathrm{~ms}, 100 \mu \mathrm{s}$.

240

241

\subsection{Size detection limits}

242 The intensity corresponding to the dissolved species or/and the background $\left(\mu_{B}\right)$ affects directly the

243 attainable size detection limit $\left(\operatorname{LOD}_{\text {size }}\right)$ through its standard deviation $\left(\sigma_{B}\right)$. Applying a $3 \sigma$

244 criterion $^{25}$ for spherical, solid, and pure nanoparticles, and estimating $\sigma_{\mathrm{B}}$ as the square root of the 245 background counts plus one ${ }^{31}$, the $\mathrm{LOD}_{\text {size }}$ is given by: 


$$
L O D_{\text {size }}=\left(\frac{18 \sigma_{B}}{\pi \rho X_{N P} K_{I C P M S} K_{M}}\right)^{\frac{1}{3}}=\left(\frac{18 \sqrt{\mu_{B}+1}}{\pi \rho X_{N P} K_{I C P M S} K_{M}}\right)^{\frac{1}{3}}
$$

247

248 where $\rho$ is the density of the nanoparticles, $X_{N P}$ the mass fraction of the element in the nanoparticle,

$249 K_{I C P M S}$ the detection efficiency (ratio of the number of ions detected versus the number of atoms

250 introduced into the ICP $)$, and $K_{M}\left(=\mathrm{AN}_{\mathrm{Av}} / M_{M}\right)$ includes the contribution from the element measured

251 (A, atomic abundance of the isotope considered; $\mathrm{N}_{\mathrm{Av}}$, Avogrado number; $M_{M}$, the atomic mass).

252

253

254

255

256

257

258

259

260

261

262

263

264

265

266

Apart from the influence of dissolved/background on LOD $_{\text {size }}$, Equation 1 includes the detection efficiency, which depends on the particular instrument. On the other hand, the relationship between the signal $R$ (ions counted per time unit) and the mass concentration $C^{M}$ of a solution of an analyte nebulized into an ICPMS can be expressed as:

$$
R=K_{\text {intr }} K_{I C P M S} K_{M} C^{M}
$$

where $K_{\text {intr }}\left(=\eta_{\text {neb }} \mathrm{Q}_{\text {sam }}\right)$ represents the contribution from the sample introduction system, through the nebulization efficiency $\left(\eta_{n e b}\right)$ and the sample uptake rate $\left(Q_{\text {sam }}\right)$, whose values are detailed in section 2. Experimental. By analysing a dissolved selenium standard and knowing the value of $K_{\text {intr }}$, the term “ $K_{I C P M S} K_{M}$ ” can be deduced from Equation 2.

Table 3 summarizes the $\operatorname{LOD}_{\text {size }}$ calculated for different selenium isotopes and dwell times in water. By monitoring the most abundant isotope ${ }^{80} \mathrm{Se}$, working with $\mathrm{H}_{2}$ as reaction gas and with a dwell time of $100 \mu \mathrm{s}$, a size detection limit of $18 \mathrm{~nm}$ could be achieved, considering: $\mu_{B}=0.0092$ counts; $\rho=4.79 \mathrm{~g} \mathrm{~cm}^{-3} ; X_{M}=1 ; \eta_{\text {neb }}=0.035 ; \mathrm{Q}_{\mathrm{sam}}=0.35 \mathrm{~mL} \mathrm{~min}{ }^{-1} ; \mathrm{A}=0.4961 ; \mathrm{N}_{\mathrm{Av}}=6.022 \mathrm{x}$ 
$26710^{23} ; \mathrm{M}_{\mathrm{M}}=78.96 \mathrm{~g} \mathrm{~mol}^{-1} ; R / C^{M}=40600 \mathrm{cps} \mathrm{L} \mu \mathrm{g}^{-1}$. Taking the above into account, monitoring ${ }^{80} \mathrm{Se}$ 268 and working in collision/reaction cell mode was concluded to be the best choice for the detection of 269 SeNPs by SP-ICPMS.

270

271 Table 3 Size detection limits for selenium nanoparticles in water, $\mathrm{nm}$

\begin{tabular}{llll}
\hline Dwell time & $\mathbf{H}_{\mathbf{2}}$ cell & ${ }^{78}$ Se, $\mathbf{L O D}_{\text {size }}$ & ${ }^{\mathbf{8 0}}$ Se, $\mathbf{L O D}_{\text {size }}$ \\
\hline \multirow{2}{*}{$5 \mathrm{~ms}$} & No & 83 & - \\
& Yes & 25 & 24 \\
\hline \multirow{2}{*}{$100 \mu \mathrm{s}$} & No & 43 & - \\
& Yes & 24 & 18 \\
\hline
\end{tabular}

273 3.3. Analysis of commercial suspensions of selenium nanoparticles

274 Two different commercial suspensions of SeNPs with nominal diameters of 50 and $100 \mathrm{~nm}$ were

275 analyzed by the developed method. Fig. 2 shows the time scans and the corresponding number size 276 distribution obtained for both commercial suspensions.

277 

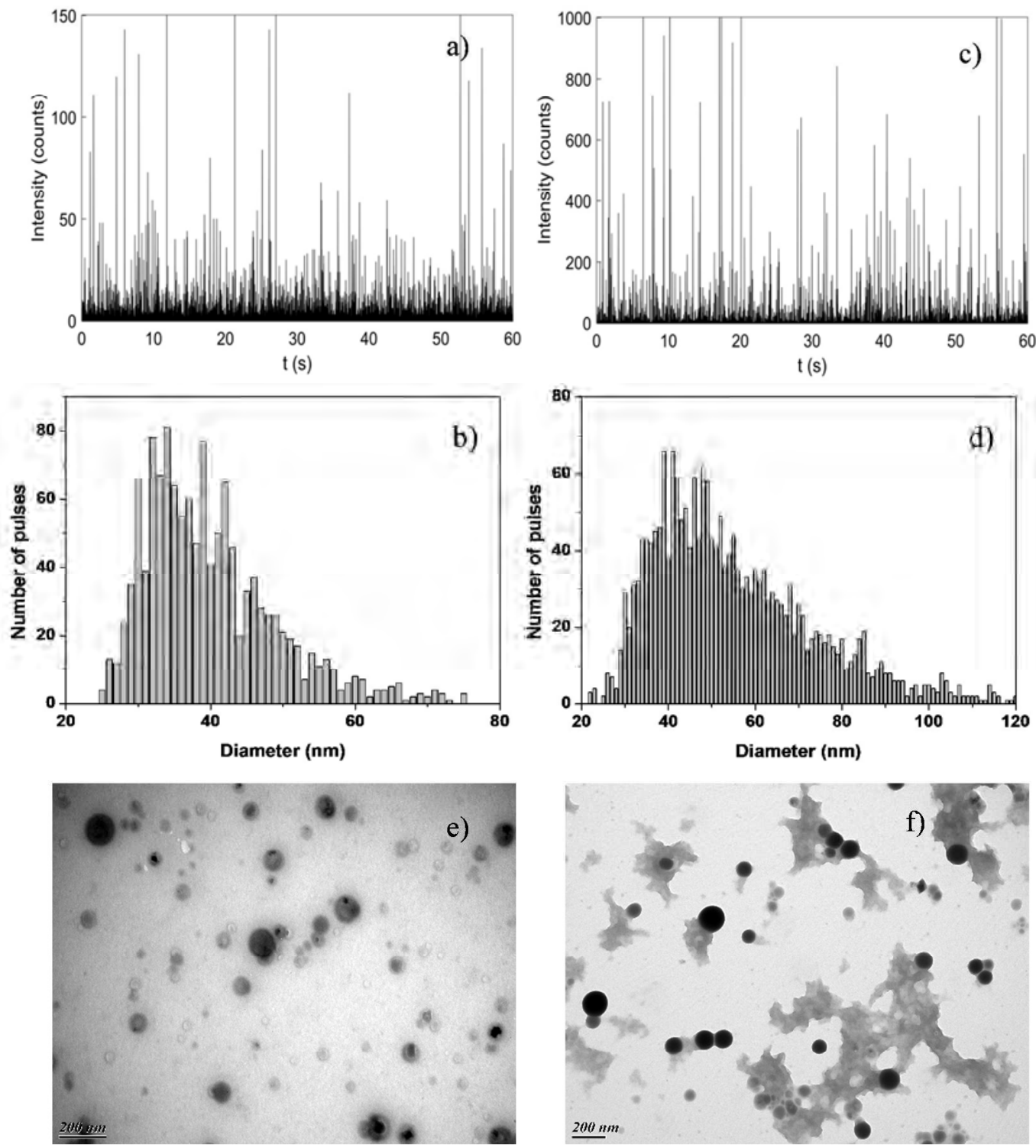

279 Fig. $2{ }^{80} \mathrm{Se}$ time scans of a) 50-nm Se nanoparticle suspension; c) 100-nm Se. Number size 280 distribution of b) 50-nm Se nanoparticle suspension; d) 100-nm Se. Dwell time: $100 \mu$ s. 281 Transmission electron microscope image of e) 50-nm Se nanoparticle suspension; f) 100-nm Se. 282 Scale bar: $200 \mathrm{~nm}$. 
284

285

286

287

288

289

290

291

292

The developed method allowed the detection of SeNPs as small as $20 \mathrm{~nm}$ in diameter. The distributions showed an average diameter of $40.2 \pm 0.4 \mathrm{~nm}$ for the nominal $50-\mathrm{nm}$ particles and of $57.1 \pm 0.1 \mathrm{~nm}$ for the nominal 100 -nm particles. TEM images for both suspensions are presented in Fig. 2e and $2 \mathrm{f}$, showing spherical particles with no significant aggregation/agglomeration and some polydispersity. The corresponding size distributions have been included in Fig. S2, showing that the average sizes are in agreement with the nominal values (60 and $101 \mathrm{~nm}$, respectively).

The disagreement between TEM and SP-ICPMS results can be explained by a different response of the ICPMS towards the dissolved and the nanoparticulate selenium forms. To prove this hypothesis, the total content of selenium in the commercial suspensions of SeNPs was determined both by direct analysis of the diluted suspensions, and after their acid digestion. The calibration was achieved with aqueous standards of selenium in water and $2 \% \mathrm{HNO}_{3}$ respectively, since a dependence of the medium on the selenium sensitivity was observed. In order to verify the completeness of the digestion procedure, the corresponding digested solutions were also measured in single particle mode. No nanoparticle signals were observed, confirming that all the selenium present was in its dissolved form or as particles below $18 \mathrm{~nm}$. The concentrations determined in water for the 50-nm and 100-nm SeNPs suspensions were $81.0 \pm 3.4 \%$ and $66.1 \pm 7.6 \%$ with regard to the concentration determined after acid digestion, respectively (Table 4). These results show that ICPMS sensitivity is dependent on the physicochemical form of selenium and on the size of the nanoparticles. If nebulization efficiency is considered equal for dissolved and particulated forms of selenium, the differences arises from the detection efficiency, most probably the less efficient atomization or ionization of selenium nanoparticles. 
306 Table 4 Determination of selenium concentration in commercial suspensions of SeNPs in mg L $\mathrm{L}^{-1}$

307 (mean \pm standard deviation)

\begin{tabular}{lll}
\hline Sample & $\mathbf{5 0 - n m}$ & $\mathbf{1 0 0 - \mathbf { n m }}$ \\
\hline Acid digestion & $148.6 \pm 5.5$ & $92.1 \pm 1.20$ \\
Suspensions in water & $120.3 \pm 2.2$ & $60.85 \pm 6.93$ \\
\hline
\end{tabular}

308

309

\subsection{Detection and characterization of biogenic selenium nanoparticles in Se-rich yeast} samples

The different behaviour observed for the dissolved and nanoparticulate forms of selenium implies that the use of dissolved selenium standards for calculations of the selenium mass per particle or the size of a selenium particle will produce a negative bias and hence SeNPs with similar selenium content or size of the targets should be used as standards.

The developed method was applied for the detection and characterization of putative selenium nanoparticles present in selenium enriched yeast.

3.4.1. Enzymatic digestion of the yeast matrix. Yeast samples were submitted to an enzymatic digestion prior to their injection onto a size exclusion column for the separation of the selenium-binding species as explained in section 2. Experimental. The effect of the digestion procedure on the stability of SeNPs (dissolution or agglomeration) was also checked. For this, a Sefree yeast sample was spiked with 100-nm SeNPs, submitted to the enzymatic digestion and analyzed by SP-ICPMS. The size distribution obtained is shown in Fig. 3. In comparison with the size distribution obtained for the original suspension (Fig. 2d), the size range was in good 
326 agreement, proving that no agglomeration process occurred. However, obtaining the full 327 distribution was hampered by the presence of a relatively high background level, suggesting the 328 presence of dissolved selenium due to the partial oxidation of the nanoparticles.

329

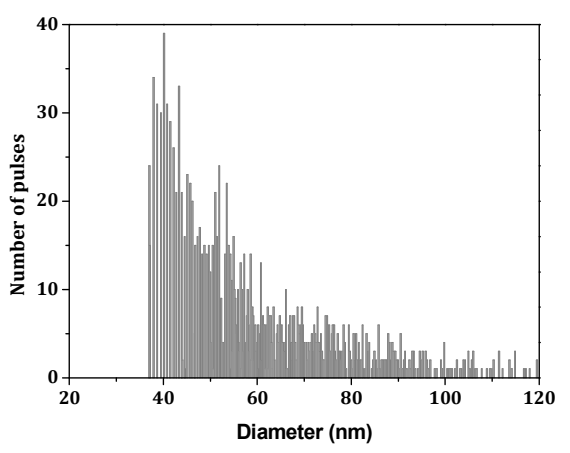

330 331

332

333

334

335

336

337

338

339

340

341

3.4.2. Detection of selenium nanoparticles in yeast. The chromatograms obtained for a Se-rich yeast sample by size exclusion chromatography with Visible and ICPMS detection are shown in Fig. 4. Low molecular weight species were eluted as a single peak at 28 minutes, whereas another selenium containing peak was observed at the exclusion volume of the column (10 min). Only the peak at the exclusion volume also showed absorption at $565 \mathrm{~nm}$, a wavelength associated to SeNPs, ${ }^{20,38}$ what suggests the presence of naturally occurring selenium nanoparticles in the yeast sample.

Furthermore, the sample of yeast after the digestion procedure (Sample A) and the collected fraction corresponding to the exclusion volume in the chromatogram (Sample A post column) were analysed by SP-ICPMS under the previously optimized conditions (monitoring ${ }^{80} \mathrm{Se}$, with $\mathrm{H}_{2}$ 
342 reaction cell, dwell time: $100 \mu \mathrm{s}$ ). The time scans obtained showed a significant number of signals

343 above the background related to the presence of selenium-bearing nanoparticles in both cases (Figs.

$3445 \mathrm{a}, \mathrm{c})$. These time scans were transformed into signals distributions (Fig. S3). A different Se-rich

345 yeast sample (Sample B) was submitted to the same procedure and analysed by SP-ICPMS. In this

346 case, only a few signals above the background were observed (Fig. 5e), meaning the presence of a

347 small amount of selenium-bearing nanoparticles. This difference may be explained by the different

348 total concentration values in the original samples. The original yeast of sample A contained 3000

$349 \mathrm{mg} \mathrm{kg}^{-1}$ while the total selenium concentration in the original yeast of sample B was $2000 \mathrm{mg} \mathrm{kg}^{-1}$.

350 On the other hand, and in order to evaluate the particle detection capabilities of the method in real

351 samples, the size detection limits of the different samples were calculated by using the background

352 signal obtained in the time scans, obtaining values of 23, 20 and $19 \mathrm{~nm}$ for Sample A, Sample A

353 post column and Sample B, respectively.

354

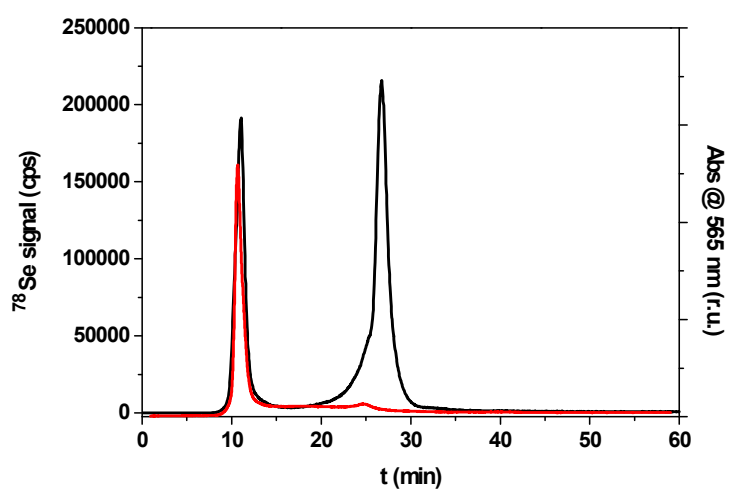

355

356 Fig. 4 Chromatograms of a selenium enriched yeast sample after the digestion procedure, obtained

357 by ${ }^{78} \mathrm{Se}$ signal (black signal) and Vis signal recorded at $565 \mathrm{~nm}$ (red line). The first peak 358 corresponds to the void volume of the column. 

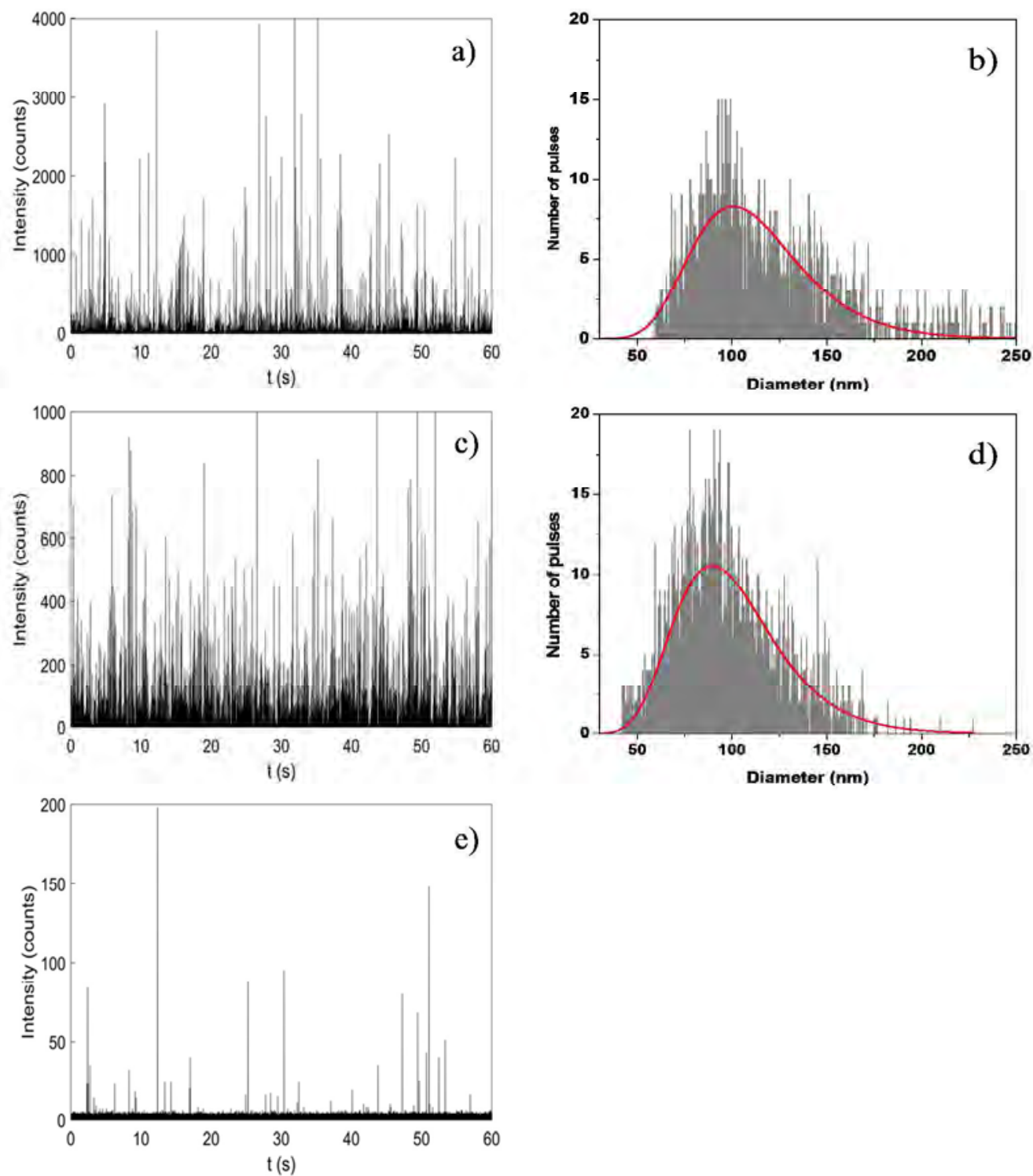

360

361 Fig. $5{ }^{80}$ Se time scans and number size distributions obtained by SP-ICPMS corresponding to a-b)

362 Sample A; c-d) Sample A post column; and time scan corresponding to e) Sample B.

363 
the mass of element per nanoparticle, which means that the conversion into size involves knowing

366 the actual composition, density and shape of the nanoparticles. Additional techniques like 367 transmission electron microscopy (TEM) and energy dispersive X-ray spectroscopy (EDS) were 368 used to learn the shape and the elemental composition of the nanoparticles present in sample A. 369 TEM images and EDS spectra obtained confirmed the presence of spherical nanoparticles whose 370 composition was associated to elemental selenium (Fig. S4). Note that due to the low concentration 371 of SeNPs in the sample, the number of particles detected in the images was too low to obtain a 372 representative histogram, although a diameter around $100 \mathrm{~nm}$ could be measured from single 373 images.

374 Once the composition and the shape of the nanoparticles were determined, the time scans 375 were transformed into size distributions (Figs. 5b, d), using the density of bulk elemental selenium $376\left(4.79 \mathrm{~g} \mathrm{~cm}^{-3}\right)$. Due to the different behaviour in the ICPMS with respect to the size and the 377 physicochemical forms of selenium, as previously discussed, and to the size of nanoparticles 378 observed by TEM $(\sim 100 \mathrm{~nm})$, a sensitivity correction factor of $66 \%$ was applied on the mass of 379 selenium per nanoparticle, calculated by using aqueous standards of selenium in water. The size 380 histogram obtained for Sample A showed a broad distribution of selenium nanoparticles, from 60 to $381200 \mathrm{~nm}$ (Fig. 5b). The size distribution was fitted into a log normal distribution and the median 382 diameter was calculated, obtaining an average median diameter ( $\mathrm{n}=5)$ of $108 \pm 4 \mathrm{~nm}$ (average \pm 383 standard deviation). On the other hand, a similar size distribution was obtained for the fraction 384 collected at the exclusion volume of the column (Sample A post column, Fig. 5d), with an average 385 median diameter of $97 \pm 3 \mathrm{~nm}$ (average \pm standard deviation). These results are in good agreement 
with the data from TEM, where nanoparticles around $100 \mathrm{~nm}$ were observed and confirmed that a process of biosynthesis of selenium nanoparticles occurred in selenium enriched yeast.

\section{Conclusions}

An analytical method based on SP-ICPMS was developed for the detection and characterization of SeNPs. The carefully optimization of parameters, including the monitored isotope, the choice of the microsecond dwell time regime and the use of collision/reaction cell, allowed the reduction of the background signal for using the most sensitive isotope of selenium. Under the optimal conditions, a size detection limit of $18 \mathrm{~nm}$ could be obtained, which represents a gain of a factor of 10 in terms of the prediction made elsewhere and the first ever single particle-ICP MS method for selenium nanoparticle analysis. The method demonstrated the presence of SeNPs with sizes from 40 to 200 $\mathrm{nm}$ in Se-rich yeast and is able to provide information about the presence and size distributions of nanoparticles at actual concentrations.

\section{Conflicts of interest}

401 There are no conflicts to declare.

402

\section{Supplementary Information}

404 Electronic supplementary information (ESI) available: Information about isotopic abundance and 405 spectral interferences for Se isotopes, time scans of ultrapure water, size distributions of SeNPs suspensions, signal distributions of samples, TEM image and EDS spectrum. 


\section{Acknowledgements}

409 The authors acknowledge Philippe Le Coustumer and the Bordeaux Imaging Center (BIC) for the

410 transmission electron microscopy and energy dispersive X-ray spectroscopy analysis. This work

411 was supported by the Spanish Ministry of Economy and Competitiveness and the European

412 Regional Development Fund, project CTQ2015-68094-C2-1-R (MINECO/FEDER) as well as by

413 the project AQUITRACES Region Aquitaine 20131206001-13010973.

414

415

\section{References}

416 1. M. Shakibaie, H. Forootanfar, Y. Golkari, T. Mohammadi-Khorsand, and M. R. Shakibaie, J. 417 Trace Elem. Med. Biol., 2015, 29, 235-241.

418 2. E. Cremonini, E. Zonaro, M. Donini, S. Lampis, M. Boaretti, S. Dusi, P. Melotti, M. M. Lleo, 419 and G. Vallini, Microb. Biotechnol., 2016, 9, 758-771.

420 3. S. Lampis, E. Zonaro, C. Bertolini, P. Bernardi, C. S. Butler, and G. Vallini, Microb. Cell Fact., $4212014,13,35$.

422 4. S. Lampis, E. Zonaro, C. Bertolini, D. Cecconi, F. Monti, M. Micaroni, R.J. Turner, C.S. Butler, 423 and G. Vallini, J. Hazard. Mater., 2017, 324, 3-14.

424 5. E. Herrero and R. Wellinger, Microb. Cell, 2015, 2, 139-149.

425 6. G. N. Schrauzer, Pure Appl. Chem., 2006, 78, 105-109.

426 7. M. P. Rayman, Br. J. Nutr., 2004, 92, 557. 
427 8. K. Bierla, J. Szpunar, A. Yiannikouris, and R. Lobinski, TrAC - Trends Anal. Chem., 2012, 41, $428 \quad 122-132$.

429

9. H. Goenaga-Infante, R. Sturgeon, J. Turner, R. Hearn, M. Sargent, P. Maxwell, L. Yang, A. 430 Barzev, Z. Pedrero, C. Cámara, V. Díaz Huerta, M. L. Fernández Sánchez, A. Sanz-Medel, K. 431 Emese, P. Fodor, W. Wolf, R. Goldschmidt, V. Vacchina, J. Szpunar, L. Valiente, R. Huertas, G. 432 Labarraque, C. Davis, R. Zeisler, G. Turk, E. Rizzio, L. G. MacKay, R. B. Myors, D. L. Saxby, 433 S. Askew, W. Chao, and W. Jun, Anal. Bioanal. Chem., 2008, 390, 629-642.

434 10. European Food Safety Authority, EFSA J., 2008, 766, 1-42.

435 11. S. Mounicou, M. Dernovics, K. Bierla, and J. Szpunar, Talanta, 2009, 77, 1877-1882.

436 12. F. A. Aborode, A. Raab, S. Foster, E. Lombi, W. Maher, E. M. Kruppa, and J. Feldmann, 437 Metallomics, 2015, 7, 1056-1066.

438 13. Z. Mester, European Symposium on Atomic Spectrometry ESAS, 2014.

439 14. S. Dhanjal and S. S. Cameotra, Microb. Cell Fact., 2010, 9, 52.

440 15. R. Avendaño, N. Chaves, P. Fuentes, E. Sánchez, J. I. Jiménez, and M. Chavarría, Sci. Rep., $4412016,6,37155$.

442 16. Y. Tan, R. Yao, R. Wang, D. Wang, G. Wang, and S. Zheng, Microb. Cell Fact., 2016, 15, 157.

443 17. A. V. Tugarova, E. P. Vetchinkina, E. A. Loshchinina, A. M. Burov, V. E. Nikitina, and A. A. $444 \quad$ Kamnev, Microb. Ecol., 2014, 68, 495-503.

445 18. A. A. Kamnev, P. V. Mamchenkova, Y. A. Dyatlova, and A. V. Tugarova, J. Mol. Struct., 2017, $446 \quad 1140,106-112$.

447 19. F. Elahian, S. Reiisi, A. Shahidi, and S. A. Mirzaei, Nanomedicine Nanotechnology, Biol. Med., $448 \quad 2017,13,853-861$. 
449

450

451

452

453

454

455

456

457

458

459

460

461

462

463

464

465

466

467

468

469

470

20. S. Dwivedi, A. A. AlKhedhairy, M. Ahamed, and J. Musarrat, PLoS One, 2013, 8, 1-10.

21. M. Palomo-Siguero, P. Vera, Y. Echegoyen, C. Nerin, C. Cámara and Y. Madrid, Spectrochim. Acta Part B J., 2017, 132, 19-25.

22.G. Moreno-Martin, M. Pescuma, T. Pérez-Corona, F. Mozzi and Y. Madrid, Anal. Chim. Acta, $2017,992,34-41$.

23. F. Laborda, E. Bolea, and J. Jiménez-Lamana, Trends Environ. Anal. Chem., 2016, 9, 15-23.

24. C. Degueldre and P. Y. Favarger, Colloids Surfaces A Physicochem. Eng. Asp., 2003, 217, 137142.

25. F. Laborda, E. Bolea, and J. Jiménez-Lamana, Anal. Chem., 2014, 86, 2270-2278.

26. F. Laborda, J. Jiménez-Lamana, E. Bolea, and J. R. Castillo, J. Anal. At. Spectrom., 2011, 26, 1362.

27. S. Lee, X. Bi, R. B. Reed, J. F. Ranville, P. Herckes, and P. Westerhoff, Environ. Sci. Technol., 2014, 48, 10291-10300.

28. J. Goossens, L. Moens, and R. Dams, Talanta, 1994, 41, 187-93.

29.S. D. Tanner, V. I. Baranov, and D. R. Bandura, Spectrochim. Acta - Part B At. Spectrosc., 2002, 57, 1361-1452.

30. H. E. Pace, N. J. Rogers, C. Jarolimek, V. A. Coleman, C. P. Higgins, and J. F. Ranville, Anal. Chem., 2012, 84, 4633.

31. F. Laborda, J. Jiménez-Lamana, E. Bolea, and J. R. Castillo, J. Anal. At. Spectrom., 2013, 28, $1220-1232$.

32. I. Feldmann, N. Jakubowski, C. Thomas, and D. Stuewer, Fresenius. J. Anal. Chem., 1999, 365, $422-428$. 
1

2

3

4

5

6

7

8

9

10

11

12

93

471 33. J. M. Marchante-Gayon, C. Thomas, I. Feldmann, and N. Jakubowski, J. Anal. At. Spectrom., $472 \quad 2000,15,1093-1102$.

473 34. I. Abad-Álvaro, E. Peña-Vázquez, E. Bolea, P. Bermejo-Barrera, J. R. Castillo, and F. Laborda, $474 \quad$ Anal. Bioanal. Chem., 2016, 408, 5089-5097.

475 35. J. J. Sloth and E. H. Larsen, J. Anal. At. Spectrom., 2000, 15, 669-672.

476 36. U. Völkopf, K. Klemm, and M. Pfluger, At. Spectrosc., 1999, 20, 53-59.

477 37. S. D. Tanner, V. I. Baranov, and U. Vollkopf, J. Am. Soc. Mass Spectrom., 2000, 15, 1261$478 \quad 1269$.

479 38. Z. H. Lin and C. R. C. Wang, Mater. Chem. Phys., 2005, 92, 591-594. 